\title{
Corrosión inducida por microorganismos en la industria papelera
}

\author{
A.A. Blanco $(*)$, I. $_{\text {Gaspar }}^{(*)}$, C. $\operatorname{Negro}^{(*)}$, J. Tijero $^{(*)}$, B. López ${ }^{(*)}$ y \\ A. Álvarez-Barrientos $(* *)$
}

Resumen De todos los problemas que aparecen en la industria de papel y cartón, la formación de depósitos microbiológicos (biofilm o slime) es uno de los más importantes, ya que causa problemas tanto en la calidad del producto (suciedad, agujeros, olores) como en el proceso (paradas no programadas, corrosión, malos olores, producción de gases tóxicos, etc.). La corrosión inducida por microorganismos en la industria papelera produce grandes pérdidas económicas debido a la necesidad de sustituir los materiales más frecuentemente. En los estudios de corrosión inducida por microorganismos (CIM) es imprescindible determinar de una forma rápida y precisa la evolución del slime sobre las superficies metálicas. Por tanto, el objetivo de este trabajo ha sido el desarrollo de una metodología que permita caracterizar la población de bacterias de los slimes de una fábrica de cartón mediante citometría de flujo multiparamétrica, tomando como parámetros la dispersión de luz en dos ángulos y la cantidad total de proteínas, como primera etapa para los estudios de corrosión inducida por microorganismos.

Palabras clave: Corrosión inducida por microorganismos. Depósito microbiológico. Bacteria. Caracterización. Citometría de flujo.

\section{Microbiological induced corrosion in the paper industry}

\begin{abstract}
Microbial deposits (slime or biofilm) formation is one of the most important problems in the paper industry. Slime formation cause a reduction of the final product quality (spots, holes, odours), as well as in the production and equipment life, due to a greater number of web breaks, down time for cleanning and maintenance of the machinery, corrosion, etc. Microbiologically-induced corrosion cause an important economic losses due to the reduction of the equipment life. In microbially-induced corosion studies is basic the rapid and precise determination of the evolution of slime growth on metallic surfaces. Thus, the goal of the present work have been the development of a methodology that leads to characterize the population of aerobic bacteria that compose the slimes of a board mill by means of multiparametric flow cytometry, using two different angles of ligth scattering and the total protein content as parameters, as first step of the studies of microbiologically-induced corrosion.
\end{abstract}

Keywords: Microbiologically-induced corrosion. Slime. Bacteria. Characterization. Flow cytometry.

\section{INTRODUCCIÓN}

En los últimos años, la industria papelera ha evolucionado hacia la fabricación en medio neutro o alcalino, la utilización de fibra secundaria y hacia el cierre del circuito del sistema de aguas. Por estas razones, las aguas de proceso en los sistemas de fabricación de papel y cartón constituyen un nicho

(*) Dpto. de Ingeniería Química. Fac. de Ciencias Químicas. Univ. Complutense de Madrid. 28040-Madrid (España).

(**) Centro de Citometría de Flujo. Fac. de Farmacia. Univ. Complutense de Madrid. 28040-Madrid (España). ecológico ideal para el crecimiento de microorganismos. Tienen un $\mathrm{pH}$ favorable, una temperatura adecuada y contienen todos los nutrientes necesarios para su crecimiento, tales como fuentes de carbono, de nitrógeno, sales minerales y oligoelementos.

En estas condiciones, los problemas asociados a la actividad microbiológica, tales como la formación de depósitos microbiológicos (biofilm o slime), la producción de gases explosivos y olores ofensivos y la corrosión inducida por microorganismos (CIM) se ven considerablemente incrementados.

La corrosión inducida por microorganismos es la corrosión que se produce directa o 
indirectamente como resultado de la actividad metabólica de los mismos (1 y 2).

Un slime consiste en un conjunto de microorganismos embebidos en una matriz exopolimérica de origen microbiano que los mantiene unidos, junto con finos, cargas y suciedad en distintas proporciones, con características físicas variables y acumulándose con tasas que varían continuamente.

La formación de slimes y la corrosión metálica se han estudiado tradicionalmente por separado, como procesos independientes que ocurren simultánea o secuencialmente. Sin embargo, dentro de un biofilm, los microorganismos son capaces de mantener un medio que es radicalmente distinto al que se encuentra en la fase líquida, en términos de $\mathrm{pH}$, oxígeno disuelto y especies orgánicas e inorgánicas. Los slimes proporcionan, además, un medio protegido para el crecimiento de las bacterias, permitiendo en la mayoría de los casos, el crecimiento de diferentes tipos de bacterias a lo largo del biofilm (3). Así, dentro de un biofilm, en diferentes estratos, pueden encontrarse diferentes tipos de bacterias con necesidades metabólicas muy diversas, como aerobios, anaerobios y facultativos (4 y 5).

Los microorganismos pueden ser responsables de la corrosión de los metales debido a diversos factores $(4,6$ y 7), tales como la formación de células de concentración de oxígeno y de iones, reacciones que se producen en los biofilms (producción de sulfuro y de ácidos, deposición de metales, interacciones metabólicas, entre otros) y la producción de polímero extracelular que facilita la existencia de condiciones anaerobias en la superficie del metal.

Previa a la colonización por microorganismos, existe una adsorción de macromoléculas en la superficie del metal. Las células posteriormente adsorbidas, aerobias, se reproducen formando colonias, produciendo ánodos y cátodos locales y formando células de aireación diferencial y dando lugar a corrosión por otros tipos de mecanismos, tales como las células de concentración de iones, interacciones polímero-metal, etc. Los biofilms maduros previenen la difusión de oxígeno, de aniones agresivos, de metabolitos y de productos de corrosión hacia el exterior del slime. Además, si la tasa de respiración aerobia a lo largo del biofilm es mayor que la tasa de difusión del oxígeno, pueden generarse zonas anaerobias debajo del biofilm que permitan el crecimiento de bacterias anaerobias.

Así, la caracterización e identificación de las poblaciones de microorganismos presentes en los distintos estratos del slime es un paso imprescindible que permite el estudio de los fenómenos de corrosión inducida por microorganismos en superficies metálicas.

Con el fin de monitorizar de una forma rápida y precisa la evolución del crecimiento del slime sobre las superficies metálicas en los estudios de corrosión inducida por microorganismos, se ha desarrollado la metodología presentada en este trabajo que permitirá la creación de una base de datos, imprescindible para los estudios de corrosión.

La citometría de flujo (CMF) es una técnica analítica que permite la medida de la dispersión de la luz y la emisión de fluorescencia debidas a la iluminación apropiada de células que fluyen individualmente frente a un sistema de detección. Esta técnica está basada en el uso de compuestos que tiene alguna especificidad estructural o funcional, proporcionando información sobre parámetros estructurales, como el contenido y el estado físico de estructuras químicamente definidas de las células y parámetros funcionales, que incluyen propiedades biológicas y actividades de la célula. De esta manera, la CMF permite la detección y cuantificación de estructuras y funciones de la célula a una elevada velocidad y de manera multiparamétrica en poblaciones homogéneas o heterogéneas de células vivas o fijadas.

\section{MATERIALES Y MÉTODOS}

\subsection{Obtención del slime}

El slime se obtuvo, en condiciones estériles, de la superficie de la máquina de papel en condiciones normales de funcionamiento de la máquina en una fábrica de cartón de la Comunidad de Madrid. Esta fábrica produce cartón de doble capa a partir de fibra $100 \%$ secundaria. Las muestras se procesaron en el laboratorio en un periodo no superior a 2 horas después de su muestreo.

\subsection{Aislamiento de las bacterias}

El slime se homogeneizó en tampón TRIS estéril y se plaqueó sobre medio TGE, suplementado con cloranfenicol (bactericida) o con actidiona (fungicida), para hacer una diferenciación previa de hongos y bacterias. Se obtuvieron cultivos puros de bacterias aerobias mediante aislamientos repetidos sobre medio TGE más actidiona.

\subsection{Preparación de las muestras para citometría de flujo}

Cada cultivo puro se traspasó a medio líquido de TGE + actidiona para obtener una suspensión de células, incubando los cultivos durante 24-48 horas a $28^{\circ} \mathrm{C}$. Al cabo de este tiempo, las células se lavaron tres veces con tampón TRIS estéril y se resuspendieron en TRIS + EDTA $(0,1 \mathrm{mg} / \mathrm{mL})$ durante $24 \mathrm{~h}$ a $3{ }^{\circ} \mathrm{C}$. Pasado este tiempo, las muestras se sonicaron durante $1 \mathrm{~min}$. Posteriormente, se prepararon dos alícuotas de $1 \mathrm{~mL}$ cada una. Una de ellas se 
TABLA I.- Descripción de los slimes muestreados

TABLE I.- Description of the slimes

\begin{tabular}{|c|c|c|c|c|}
\hline Slime & $\begin{array}{c}\text { Días de } \\
\text { crecimiento* }\end{array}$ & Peso seco $(\%)$ & Color & Lugar de muestreo \\
\hline 1 & 15 & 5.104 & Marrón & Final parte húmeda \\
2 & 21 & n.d.** & Marrón oscuro & Final parte húmeda \\
3 & 7 & 5.887 & Marrón & Final parte húmeda \\
\hline
\end{tabular}

* Tomados a partir de la última parada para limpieza de la máquina. ** n.d. no determinado.

conservó sin ningún tipo de tratamiento, para ser utilizada como control. La otra se tiñó con un tinte fluorescente que tiñe proteínas, el isotiocianato de fluoresceína (FITC) (Sigma, EE.UU.) a una concentración de $0,1 \mathrm{mg} / \mathrm{mL}$ en tampón TRIS durante $40 \mathrm{~min}$. Al cabo de ese tiempo, se lavaron las células con tampón para eliminar el FITC y se analizaron por citometría inmediatamente.

\subsection{Citometría de flujo}

Para este trabajo se utilizó un citómetro Bryte-HS (BioRad). Se recogieron datos en modo list, que se procesaron mediante el software WinBryte (BioRad).

\subsection{Caracterización bacteriana bioquímica y morfológica}

La caracterización bacteriana se realizó mediante la tinción Gram de los cultivos puros y su creci- miento en medio $\mathrm{O} / \mathrm{F}$ en condiciones aerobias y ananerobias.

\section{RESULTADOS Y DISCUSIÓN}

\subsection{Descripción de los slimes}

Se muestreó slime tres veces. Las características de los slimes muestreados se describen en la tabla I.

\subsection{Caracterización morfológica y bioquímica de las especies aisladas}

Se obtuvieron 10 cultivos puros diferentes. La caracterización morfológica y bioquímica de los mismos aparece en la tabla II. Las características de las especies encontradas en estos slimes es similar a las de las especies encontradas habitualmente en las fábricas de papel $(5,8$ y 9$)$.

TABLA II.- Caracterización morfológica y bioquímica de los cultivos puros obtenidos

TABLE II.-Morphological and biochemical characterization of pure cultures

\begin{tabular}{|c|c|c|c|c|c|}
\hline \multirow{2}{*}{ Nombre } & \multirow{2}{*}{$\begin{array}{l}\text { Origen del } \\
\text { Slime }\end{array}$} & \multirow{2}{*}{ Forma } & \multirow{2}{*}{ Gram } & \multicolumn{2}{|c|}{$\mathrm{O} / \mathrm{F}$} \\
\hline & & & & Aerobio & Anaerobio \\
\hline $2 \mathrm{C} 2$ & 1 & Bacilo & Positivo & n.d.* & n.d.* \\
\hline $4 \mathrm{C} 1$ & 1 & Coco & Positivo & n.d.* & n.d.* \\
\hline 5 & 2 & Coco & Positivo & $+1-$ & $+1-$ \\
\hline $6 \mathrm{D}$ & 3 & Coco & Positivo & n.d.* & n.d.* \\
\hline $6 \mathrm{HA}$ & 3 & Coco & Positivo & $+1+$ & $-1-$ \\
\hline $6 \mathrm{HB} 1$ & 3 & Bacilo & n.d.** & n.d.* & n.d.* \\
\hline $6 \mathrm{~J}$ & 3 & Coco & Positivo & $+1-$ & $+/+$ \\
\hline $6 \mathrm{~K}$ & 3 & Coco & Positivo & $-1-$ & $-1-$ \\
\hline $6 \mathrm{M}$ & 3 & Coco-bacilo & Positivo & $-1-$ & $-1-$ \\
\hline $6 \tilde{\mathrm{N}}$ & 3 & Coco & Positivo & $-1-$ & $-1-$ \\
\hline
\end{tabular}

*n.d. no determinado. 
$\mathbf{A}$

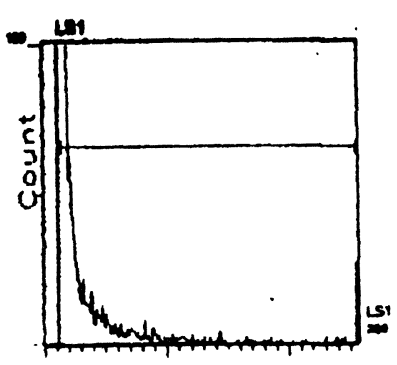

C

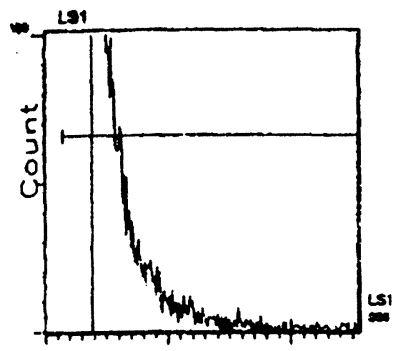

B
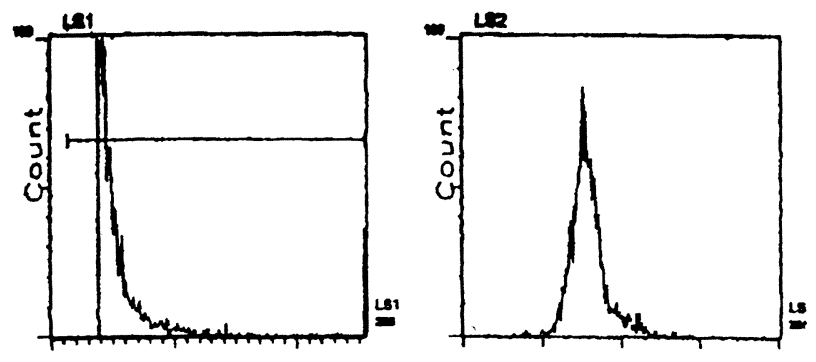

D
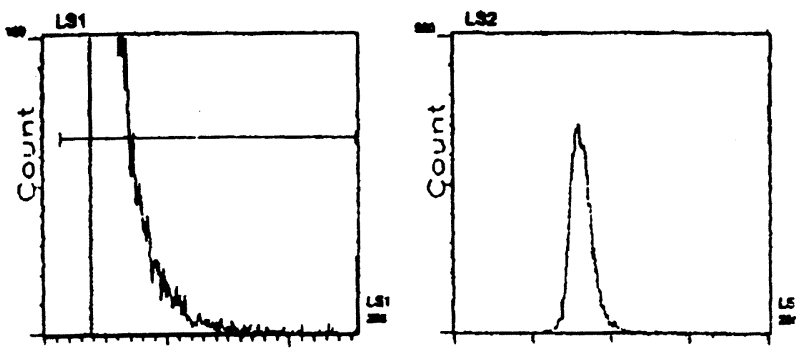

FIG. 1.- Gráficas de dispersión en ángulo cónico pequeño (LS1) y de dispersión de luz en ángulo cónico grande (LS2) de varios cultivos puros. A-4C1. B-6HA. C-6J. D-6K.

FIG. 1.- Graphics of forward scatter and wide angle scatter (LS1 and LS2) of several pure cultures. A-4C1. B-6HA. C-6J. D-6K.

\subsection{Caracterización citométrica de los cultivos puros}

En la figura 1 aparecen las gráficas de dispersión en ángulo cónico pequeño (LS1) y de dispersión de luz en ángulo cónico grande (LS2) de varios de los cultivos puros obtenidos. En la figura 2 se muestran los diagramas de puntos de la intensidad de fluorescencia en verde (FL1) frente a la dispersión de luz en ángulo cónico grande (LS2) del resto de las especies puras aisladas.

La FCM multiparamétrica recoge datos de dispersión de luz en uno o más ángulos y la fluorescencia debida a la utilización de colorantes fluorescentes con alguna especificidad funcional o estructural. Mientras que la dispersión de luz en dos ángulos permite caracterizar distintas poblaciones bacterianas, el uso de estos colorantes incrementa considerablemente la capacidad de discriminación entre distintas especies bacterianas (10). Habitualmente, los tintes fluorescentes que se utilizan para la caracterización de microorganismos son colorantes para ácidos nucleicos y proteínas. Estos colorantes fluorescentes, utilizados por separado o de manera conjunta, han permitido la caracterización de poblaciones bacterianas de diversos orígenes, como muestras clínicas, medioambientales e industriales (10-12).

\section{Agradecimiento}

Los autores desean hacer constar su agradecimiento a la Comisión Interministerial de Ciencia y Tecnología (CICYT) por la financiación del proyecto de investigación (QUI97-0666-CO3-03) en el que se enmarca este trabajo. Asimismo, desean agradecer a la Papelera del Jarama su colaboración en la obtención de muestras para la realización de este trabajo.

\section{REFERENCIAS}

(1) Von Holy, A. Paper Southern Africa, septiembre/ octubre,1985: 12-16.

(2) Cloete, T.E., Brözel, V.S. y Von Holy, A. Int. Biodeteriorat. Biodegradat., 29, 1992: 299-341.

(3) LitTle, B., Wagner, P. y Mansfeld, F. Int. Mat. Rev., 36 (6), 1991: 253-272.

(4) Ford, T. y Mitchell, R. Adv. Mic. Ecol., 11, 1990: 231262.

(5) Blanco, M.A., Gaspar, I., Negro, C. y Tijero, J. Inv. Téc. Papel, 127, 1996: 49-79.

(6) Characklis, W.G. y Cooksey, K.E. Adv. Appl. Microbiol., 29, 1983: 93-138

(7) Watkins Borenstein, S. Microbiologically Influenced Corrosion Handbook. Woodhead Publishing Limited, Cambridge, 1994: 8.

(8) SAnborn, J.R. Paper Trade J., febrero, 1965: 42-49. 
$\mathbf{A}$

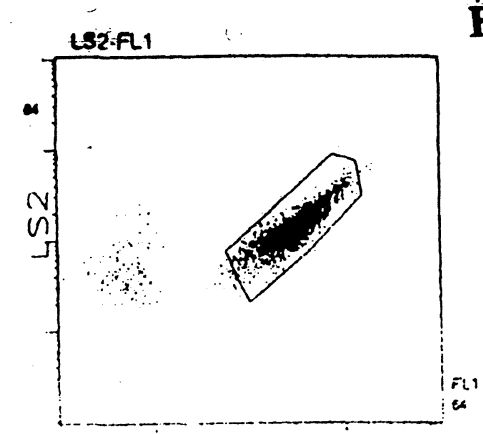

D

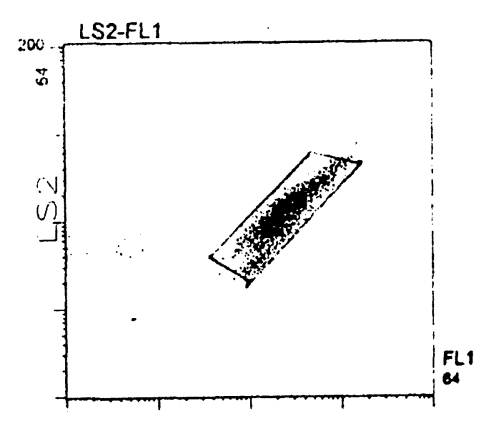

B

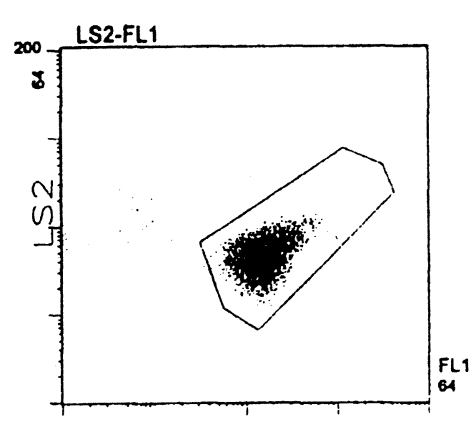

$\mathbf{E}$

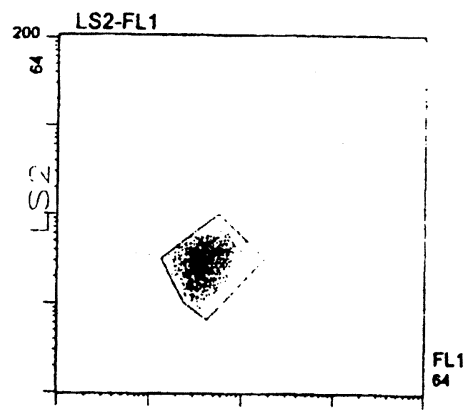

C

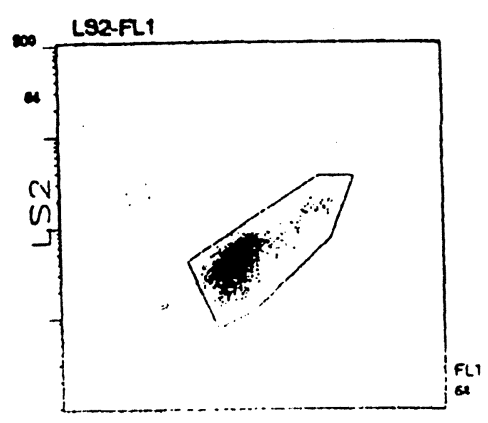

$\mathbf{F}$

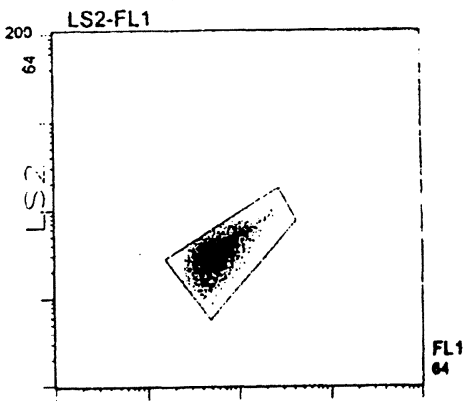

FIG. 2.- Diagramas de puntos de la intensidad de fluorescencia en verde (FL1) frente a la dispersión de luz en ángulo cónico grande (LS2). A-2C2. B-5. C-6D. D-6HB1. E-6M. F-6 ̃.

FIG. 2.-Dot plots of wide angle scatter (LS2) versus green fluorescence (FL1). A-2C2. B-5. C-6D. D-6HB1. E-6M. F-6N.

(9) Harju-Jeanty, P. y VÄÄtänen, P. Paperi ja Puu-Papper och Trä, 3, 1984: 245-259.

(10) Davey, H.M. y Kell, D.B. Microb. Rev., 60 (4), 1996: 641-696.

(11) Allman, R., Hann, A.C., Manchee, R. y Lloyd, D. $J$. Appl. Bacteriol., 73, 1992: 438-444.
(12) Allman, R., Manchee, R. y Lloyd, D. Flow Cytometry in Microbiology. Springer-Verlag, Londres (R.U.), 1992: 27.

(13) Miller, J.S. y Quarles, J.M. Citometry, 11, 1990: 667675. 